\title{
Anisotropic velocity models for (3-D) seismic imaging of the Lower Seve Nappe in Jämtland, Sweden
}

\author{
Felix Kästner ${ }^{\oplus},{ }^{1,2}$ Dirk Klaeschen, ${ }^{2}$ Christian Berndt, ${ }^{2}$ Simona Pierdominici ${ }^{1}$ and \\ Peter Hedin ${ }^{3,4}$ \\ ${ }^{1}$ Helmholtz Centre Potsdam, GFZ German Research Centre for Geosciences, 14473 Potsdam, Germany. E-mail: kaestner@gfz-potsdam.de \\ ${ }^{2}$ GEOMAR Helmholtz Centre for Ocean Research Kiel, 24148 Kiel, Germany \\ ${ }^{3}$ Geological Survey of Sweden (SGU), 75236 Uppsala, Sweden \\ ${ }^{4}$ Department of Earth Sciences, Uppsala University (UU), 75236 Uppsala, Sweden
}

Accepted 2021 August 16. Received 2021 April 16; in original form 2021 June 25

\begin{abstract}
S UMMAR Y
Strong anisotropy of seismic velocity in the Earth's crust poses serious challenges for seismic imaging. Where in situ seismic properties are not available, the anisotropy can be determined from velocity analysis of surface and borehole seismic profiles. This is well established for dense, long-offset reflection seismic data. However, it is unknown how applicable this approach is for sparse seismic reflection data with low fold and short offsets in anisotropic metamorphic rocks. Here, we show that anisotropy parameters can be determined from a sparse 3-D data set at the COSC-1 borehole site in the Swedish Caledonides and that the results agree well with the seismic anisotropy parameters determined from seismic laboratory measurements on core samples. Applying these anisotropy parameters during 3-D seismic imaging improves the seismic image of the high-amplitude reflections especially in the vicinity of the lower part of the borehole. Strong reflections in the resulting seismic data show good correlation with the borehole-derived lithology. Our results aid the interpretation and extrapolation of the seismic stratigraphy of the Lower Seve Nappe in Jämtland and other parts in the Caledonides.
\end{abstract}

Key words: Composition and structure of the continental crust; Crustal imaging; Seismic anisotropy.

\section{INTRODUCTION}

Thrust sheets are common tectonic features in the Earth's crust associated with mountain building processes. Reflection seismic imaging of these zones and associated structures such as shear zones is challenging because of the generally very complex subsurface geology, which often is affected by a considerable anisotropy of seismic velocity (e.g. Almqvist et al. 2013). Strong topography and rugged terrain further impede the processing and image quality, while low spatial coverage of sources and receivers reduces the spatial resolution of the seismic data (e.g. Yilmaz 2001; Liu et al. 2005). In addition, poorly constrained velocity information in connection with the strong seismic anisotropy can result in large uncertainties in the seismic stratigraphy, which hampers the correct localization of reflections and their correlation with lithology, for example from core or borehole data (see e.g. Elger et al. 2021).

The Seve Nappe Complex (SNC) is a prominent thrust sheet (so-called nappe) in the central Scandinavian Caledonides, which is investigated by the COSC-1 drilling project with the aim to better understand deep orogenic processes in mountain belts (Gee et al. 2010; Lorenz et al. 2015b). The allochthonous rocks of the SNC are characterized by a long tectono-metamorphic history. During the continental collision between Laurentia and Baltica, slivers of rocks from the continent-ocean transition zone were first subducted to mid-lower crustal levels before being exhumed and transported onto the Baltoscandian platform by crustal shortening involving a complex tectonostratigraphic succession. In Jämtland the SNC of the Middle Allochthon is divided into the Lower, Middle, Upper Seve Nappes comprising mostly metasedimentary rocks and mafic intrusions characterized by an inverse metamorphic grade ranging from greenschist facies at the base to amphibolite, granulite and locally eclogite facies (e.g. Gee et al. 2008, 2013; Ladenberger et al. 2014). Below the SNC lie the lower nappes of the Middle Allochthons including the Särv and Offerdal Nappes, which are composed of lower-grade metamorphosed clastic and carbonate sediments intruded by Ediacaran dike swarms from the Baltoscandian margin. These are underlain by the metasedimentary successions of the Lower Allochthon, which are derived from the Baltoscandian platform and of even lower metamorphic grade. At the Caledonian front, a thin low-angle thrust zone with Cambrian alum shale at the base of the Lower Allochthon separates the allochthonous units from the underlying Autochthonous Precambrian basement (Gee 
et al. 2010). A detailed description of the geology and tectonostratigraphy in the vicinity of the COSC-1 borehole can be found, for example in Lorenz et al. (2015b) and Hedin et al. (2016).

The SNC in Jämtland was previously imaged by regional seismic reflection surveys (Juhojuntti et al. 2001; Hedin et al. 2012). While the Central Caledonian Transect (Juhojuntti et al. 2001) did not resolve much of the relatively shallow $\mathrm{SNC}$, the COSC reflection seismic imaging of the SNC and underlying thrust sheets revealed an overall high reflectivity (seismic amplitude) but low reflection continuity (seismic coherence) with a relative diffuse, almost chaotic, reflection pattern (Hedin et al. 2012; Juhlin et al. 2016). Within the scope of the COSC-1 drilling project (Lorenz et al. 2015b), reflection seismic data were acquired using a combination of 2-D long offset seismic profiles (Simon et al. 2017), a limited 3-D seismic data set (Hedin et al. 2016) and vertical seismic profiling (Krauß 2018). Below about $2 \mathrm{~km}$ depth, both 2-D and 3-D seismic data show an overall good reflection image of the tectonic nappe and basement structures that correlates well with previously acquired 2-D seismic profiles (Hedin et al. 2016; Simon et al. 2017, 2019). Especially for the long offsets, these previous studies have shown great improvements in the reflection images of the deep crustal structures (i.e. $2-9 \mathrm{~km}$ below sea level). Seismic imaging revealed that many of the dominant reflections are part of the Precambrian basement or at the transition zone between Middle and Lower Allochthons and the basement (Simon et al. 2017, 2019). Elger et al. (2021) show that some of the reflections can be traced through the different seismic profiles correlating well with surface geology.

The 3-D seismic data set (Hedin et al. 2016) provides a first highresolution image of the lower parts of the SNC. This image indicates a pronounced reflectivity but generally low coherence of reflections that originate from the subsurface that is penetrated by the borehole. Thus, the seismic stratigraphy of the Lower Seve Nappe is only poorly constrained as the 2-D and 3-D seismic data showed large misfits of reflections in the uppermost $2.5 \mathrm{~km}$ (Elger et al. 2021). A reason for this can be the presence of seismic anisotropy. Seismic laboratory measurements of rocks of the Lower Seve Nappe show considerable anisotropy especially within the lower borehole section (Wenning et al. 2016; Kästner et al. 2020a). This has to be taken into account during seismic processing and imaging (Simon et al. 2017, 2019). Krauß (2018) used an updated time-depth conversion from zero-offset VSP data (Krauß et al. 2020), which relocated reflections by several hundreds of meters in the vicinity of the borehole. Thus, a more thorough investigation of seismic anisotropy on the seismic imaging is required.

In this study, we assess the feasibility of determining seismic anisotropy parameters from the 3-D seismic data set (Hedin et al. 2016) in combination with velocities from zero-offset VSP (Krauß et al. 2020) and surface tomography data (Simon et al. 2017) at the COSC-1 borehole site. Methods for the estimation of anisotropy parameters from seismic field data are known for many years (e.g. White et al. 1983; Gaiser 1990; Alkhalifah \& Tsvankin 1995; Isaac $\&$ Lawton 2004) and have been successfully applied for dense offset reflection surveys in sedimentary basins and shale formations (e.g. Elapavuluri \& Bancroft 2002; Grechka et al. 2007; Tsvankin et al. 2010 and references therein). Here seismic anisotropy parameters will be derived and tested for a very limited 3-D geometry with small offsets and particularly low fold in a metamorphic environment. The anisotropy parameters derived from seismic laboratory measurements on core samples (Wenning et al. 2016; Kästner et al. 2020a) provide an ideal calibration and verification of this approach in this tectono-metamorphic setting. To investigate the effect of the different anisotropy models on the seismic imaging we re-processed the limited 3-D seismic data using anisotropic Kirchhoff pre-stack depth migration. The resulting reflection image provides new constraints about the seismic stratigraphy and helps to improve the interpretation of the high-amplitude reflections within the Lower Seve Nappe.

\section{DATA AND METHODS}

\subsection{Reprocessing of 3-D seismic data}

The 3-D seismic data were originally processed by Hedin et al. (2016) using a standard processing scheme comprising deconvolution, spectral equalization, spherical divergence compensation, automatic gain control (AGC) and different filters to increase the signal-to-noise ratio of the data. The authors reported major challenges in the processing due to complicated static corrections because of topographic variations, complex geology with strong anisotropy and two different source types used for the near to intermediate and far offset shots, respectively. The original data were rectangularly binned at $20 \mathrm{~m} \times 60 \mathrm{~m}$ bin size covering an area of about $17 \mathrm{~km}^{2}$, centred on approximately $1.5 \mathrm{~km}^{2}$ receiver spread (Fig. 1). This means that many common midpoint (CMP) bins ( $\sim 57$ per cent) contain no seismic data (Hedin et al. 2016). The highest fold is in the vicinity of the COSC-1 borehole, which is located at the centre of the survey layout (Fig. 1). The limited 3-D acquisition geometry exhibits an acquisition footprint in the azimuthal and offset coverage because of irregular source spacing (Hedin et al. 2016). A complete list of the original acquisition parameters of this 3-D seismic survey can be found in Hedin et al. (2016, table 1 therein).

Here, we re-processed the seismic data starting with a preprocessed data set of decoded traces that have already been preprocessed with trace editing and sorting, vertical stacking, deconvolution and static corrections. The static corrections included refraction static shifts based on the first arrivals to remove near-surface velocity anomalies by an application of a CMP-based floating datum correction to reduce topographic effects. We re-processed the data using the Omega Geophysical Processing Platform by Schlumberger. Initially, the input data were set up with a new geometry, which is linked to a local (CMP: $x$ and $y$ ) and a global (SWEREF99 TM) reference coordinate system.

Similar to the original processing one of the main difficulties is related to static and dynamic corrections of the input data due to a relatively pronounced surface topography at the source locations ( $c$. 397-637 $\mathrm{m}$ above sea level) and the whole imaging region (c. 375$828 \mathrm{~m}$ ). The floating CMP static previously applied to the input data was removed and sources and receivers were relocated to the surface topography as defined by an imported external topography model (ASTER GDEM version 2). A new CMP geometry with a $20 \mathrm{~m} \times$ $20 \mathrm{~m}$ bin size was applied covering a rectangular area as seen in Fig. 1. To further increase the coherence of the data, a frequencydependent amplitude balancing and a random noise attenuation filter was applied in the shot-gather domain. In the uppermost $500 \mathrm{~m}$, $0.2 \mathrm{~s}$ two-way time below the surface, the data quality is adversely affected by noise from different sources (e.g. ground roll, varying source signals) and also the deeper part, below $3000 \mathrm{~m}, 1.0 \mathrm{~s}$ twoway time, shows a reduced signal-to-noise ratio.

In the final processing step the data were migrated using an anisotropic 3-D Kirchhoff pre-stack depth migration. The amplitude preserving Kirchhoff pre-stack depth migration (Schneider 1978; Zhang et al. 2000; Bleistein et al. 2001) is based on a traveltime 


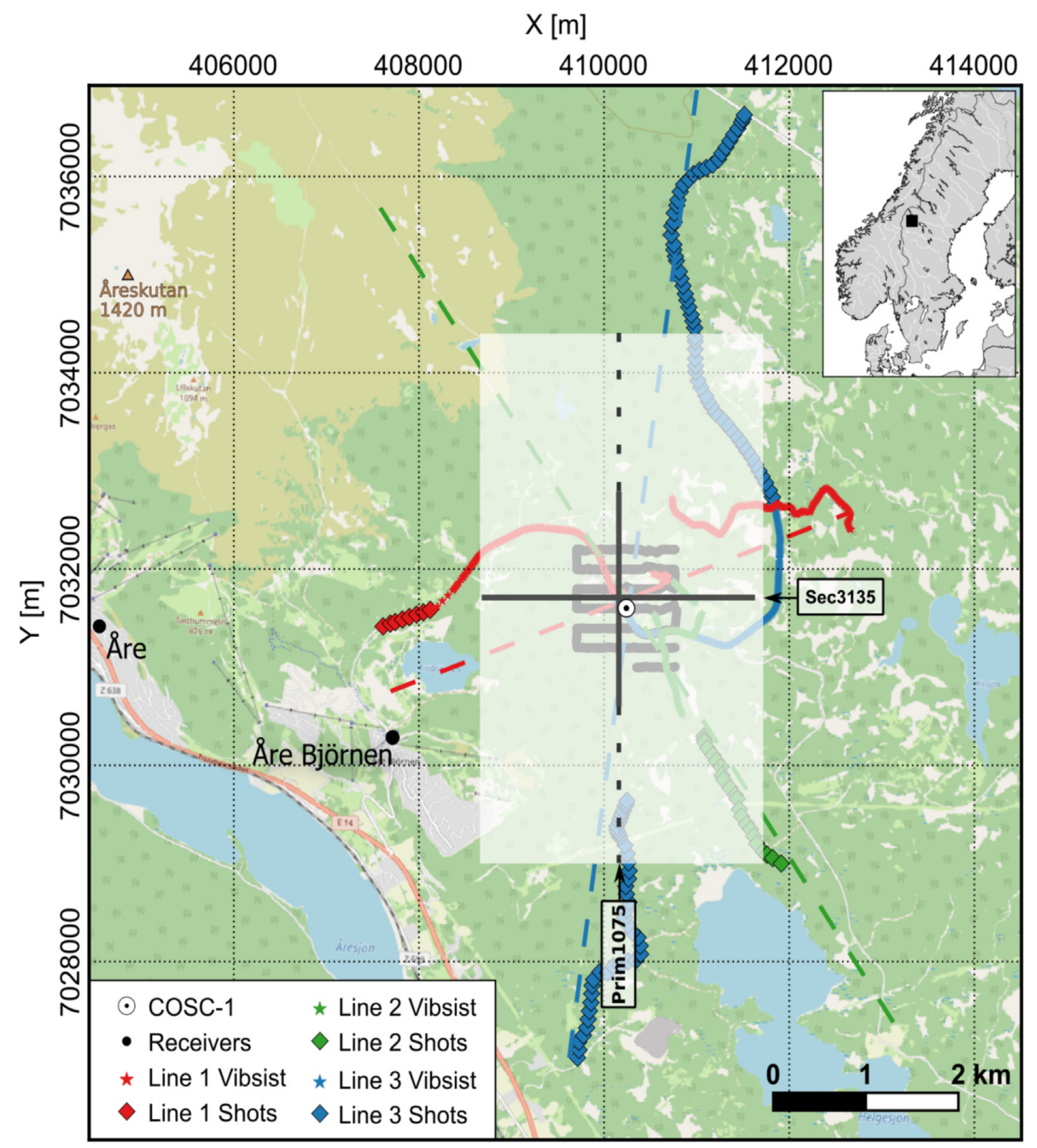

Figure 1. Seismic survey map at the COSC-1 borehole site in Jämtland, Sweden $\left(63^{\circ} 24^{\prime} 11^{\prime \prime} \mathrm{N}, 13^{\circ} 12^{\prime} 11^{\prime \prime} \mathrm{E}\right.$; UTM zone $\left.33 \mathrm{~V}\right)$. Shown are the 3-D seismic reflection survey (Hedin et al. 2016) and the projected 2-D tomographic lines (dashed lines; Simon et al. 2017) used for later velocity models. The highlighted rectangle indicates the extent of the CMP grid used in this re-processing.

calculation using a second-order Runge-Kutta wave front construction. The traveltimes were calculated for sources and receivers from the topographic surface downward into the 3-D subsurface volume where rays of maximum energy were selected. An antialiasing operator was implement by a pre-filter to each input trace (Gray 2013). The migrated image cube was corrected by the migrated cell-fold and not scaled further as the migration is amplitude preserving. In contrast, Hedin et al. (2016) have applied a post-stack time migration from a floating CMP datum based on a finite-difference algorithm, which generally comes at lower computational costs but may give results not as accurate as from pre-stack migration.

\subsection{Velocity models}

The background velocities used in the re-processing and migration are based on the velocity models previously generated within three independent seismic experiments. Vertical velocities were derived from first-arrival traveltimes of zero-offset vertical seismic profiling data from the COSC-1 borehole (Krauß 2018; Krauß et al. 2020). These velocities are the most reliable velocities at the borehole location as they show a good correlation with downhole sonic data (Kästner et al. 2020a). The horizontal or lateral velocity field
( $\mathrm{v}_{\text {Tомо }}$ ) is based on the velocity model derived by Simon et al. (2017), who calculated a subsurface velocity model based on wideangle first-arrival tomography. These tomography lines correspond to the same source profiles that were used for the limited 3-D seismic reflection survey (Fig. 1). The 3-D normal moveout velocities $\left(\mathrm{v}_{\mathrm{NMO}}\right)$, or short-spread moveout velocities, were determined and used for stacking and later spatially smoothed for the application in the post-stack time migration from Hedin et al. (2016). Prior to our full 3-D-pre-stack depth migration, these velocities were first converted to interval moveout velocities and then converted to the depth domain. It must be noted that $\mathrm{v}_{\mathrm{NMO}}$ have large uncertainties because of the limited offset, moderate reflection continuity and sparse coverage in the subsurface. These velocities may be underestimated due to the reduced moveout sensitivity at small offsets. Each velocity field was interpolated and extrapolated to the entire survey area.

\subsection{Seismic anisotropy models}

To investigate the effect of seismic anisotropy on the seismic imaging, we assumed an anisotropic medium with a vertical axis of symmetry, that is vertical transverse isotropy. Thomsen (1986) showed 


\section{Wavefronts}

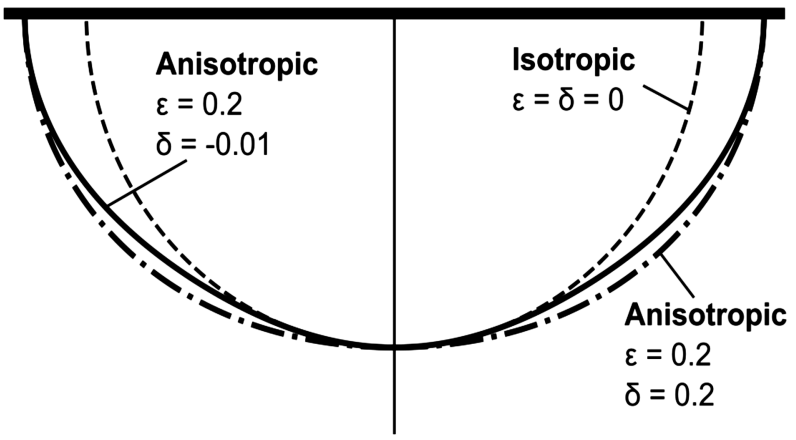

Figure 2. Schematic of seismic wave propagation in a homogeneous anisotropic half-space with vertical axis of symmetry showing the angle dependence of the calculated wave fronts for an isotropic and two anisotropic cases using different values of $\varepsilon$ and $\delta$ (adapted from Thomsen 1986).

that such a model can be described by five elastic constants that he combined to the three Thomsen parameters $\varepsilon, \gamma$ and $\delta$. Fig. 2 visualizes how these parameters control elastic wave propagation in an anisotropic medium. The angle-dependent seismic phase velocities for weakly anisotropic media can be written in terms of the Thomsen parameters as:

$v_{P}(\theta)=v_{P}(0)\left\{1+\delta \sin (\theta)^{2} \cos (\theta)^{2}+\epsilon \sin (\theta)^{4}\right\}$,

$v_{S V}(\theta)=v_{S}(0)\left\{1+\left(\frac{v_{p}(0)}{v_{S}(0)}\right)^{2}(\epsilon-\delta) \sin (\theta)^{2} \cos (\theta)^{2}\right\}$,

$v_{S H}(\theta)=v_{S}(0)\left\{1+\gamma \sin (\theta)^{2}\right\}$,

where $\theta$ is the angle from the axis of symmetry and $v_{P}(0)$ and $v_{S}(0)$ are the $P$ - and $S$-wave velocities in the direction of the symmetry axis (here the vertical or $z$-axis). In these expressions, $\varepsilon$ and $\gamma$ describe the vertical to horizontal differences in the $P$-and $S$-wave velocities, respectively, whereas $\delta$ describes the effects at intermediate angles, i.e. the bulging or deviation of the wave front from an ellipse (Fig. 2).

In this study, we derive the Thomsen parameters from available seismic laboratory data of core samples (constant parameter models) as well as from seismic velocity analysis of combined zerooffset borehole and multi-offset surface reflection profiles, which are described in detail in the following subsections.

\subsubsection{Sample-based anisotropy parameter models}

We have tested five different constant parameter models based on seismic laboratory measurements on core samples (Wenning et al. 2016; Kästner et al. 2020a,b). For the first model (model 1), we applied the Thomsen parameters by Simon et al. $(2017 ; \varepsilon=0.03, \delta=$ 0.3 ), who derived a first anisotropic velocity model for the COSC-1 borehole. In their proposed model, $\varepsilon$ was based on sample measurements of a calc-silicate gneiss (Wenning et al. 2016; core sample 243-2), while $\delta$ was calculated based on a best-fitting approach of first-arrival times from a combined borehole and surface seismic survey (Simon et al. 2017). In model 1.1, we have modified model 1 derived from Simon et al. (2017) applying an elliptical anisotropy assumption (i.e. $\varepsilon=\delta$ ), in order to investigate the effect of the parameter $\delta$ on the seismic imaging (see Table 1). In model 2, we used the mean seismic anisotropy based on seismic laboratory measurements of 16 core samples, which were taken from various lithologies and depths from the COSC-1 drill cores (Wenning et al. 2016;
Kästner et al. 2020a). In model 3, we chose a mean anisotropy parameter based on the seismic anisotropy profile proposed in Kästner et al. (2021), which was derived from an anisotropic-facies approach of the COSC-1 core lithology. Similarly, to obtain model 4, we determined two averages for two prominent depth ranges $(-500$ to $1250 \mathrm{~m} ; 1250$ to $2000 \mathrm{~m}$ ), according to the general trend of the facies-based anisotropy profile (Table 1, Fig. 3). Since $\delta$ was not determined from seismic laboratory experiments, we applied elliptical anisotropy (i.e. $\varepsilon=\delta$ ) for the sample-derived parameter models (i.e. models 1.1, 2, 3 and 4). Here, and also in the previous study by Simon et al. (2017), the velocity profile measured by the zerooffset VSP survey from the COSC-1 borehole (Krauß 2018; Krauß et al. 2020) served as the reference vertical velocity model, which were calculated from averaged interval velocities of the $P$-wave first-arrival times. Table 1 lists the previously described models and Thomsen parameters applied for anisotropic imaging. In this study, we only consider $P$-wave reflection data, thus, only $\varepsilon$ and $\delta$ are of practical relevance. However, for completeness, $\gamma$ is also listed as it may be valuable in future modelling studies.

\subsubsection{Seismic anisotropy from field data}

In addition to the constant parameter models, we have determined seismic anisotropy parameters using the velocity information from the borehole and surface seismic data. Based on the three velocity fields, $\mathrm{v}_{\mathrm{VSP}}, \mathrm{v}_{\mathrm{TOMO}}$ and $\mathrm{v}_{\mathrm{NMO}}$ (Fig. 4), we determined the Thomsen parameters $\varepsilon$ and $\delta$, as follows (Thomsen 1986; Alkhalifah \& Tsvankin 1995; Xiao et al. 2005):

$\epsilon=0.5 \cdot\left[\left(\frac{\mathrm{v}_{x}}{v_{z}}\right)^{2}-1\right]$,
$\delta=0.5 \cdot\left[\left(\frac{v_{n}}{v_{z}}\right)^{2}-1\right]$.

In these equations, $\mathrm{v}_{\mathrm{z}}$ corresponds to the vertical velocities given by the zero-offset VSP velocities ( $\mathrm{v}_{\mathrm{VSP}}$; Fig. $\left.4 \mathrm{c}\right) ; \mathrm{v}_{\mathrm{n}}$ corresponds to the near-spread NMO velocities ( $\mathrm{v}_{\mathrm{NMO}}$; Fig. $\left.4 \mathrm{~d}\right)$; and $\mathrm{v}_{\mathrm{x}}$ corresponds to the velocities from surface tomography ( $\mathrm{v}_{\mathrm{TOMO}}$; Fig. $4 \mathrm{e}$ ). For the horizontal velocity field, we re-gridded and interpolated the velocities from the surface seismic tomography data, which cover about the uppermost $0.1-0.5 \mathrm{~km}$ depth (Simon et al. 2017), and extrapolated them linearly up to $6.5 \mathrm{~km} \mathrm{~s}^{-1}$ to a depth of $600 \mathrm{~m}$. Below, we set them constant, that is to $6.5 \mathrm{~km} \mathrm{~s}^{-1}$ at depths greater than $600 \mathrm{~m}$. Following above equations, the computed $\varepsilon$ and $\delta$ parameters vary both laterally and vertically in the image area (Fig. 4). For comparison, we have calculated the averaged values of $\varepsilon$ and $\delta$ at the borehole location for two depth intervals from -250 to $1250 \mathrm{~m}$ and from 1250 to $2000 \mathrm{~m}$, which are also shown in Fig. 3 (model ed) and Table 1.

\section{RESULTS}

For the visual comparison of the results, we chose the two perpendicular 2-D sections of the 3-D seismic cube that are closest to the COSC-1 borehole location (Fig. 1) providing relatively high fold and good image quality. The cross-line section is oriented nearly $\mathrm{S}-$ $\mathrm{N}$ (Prim1075; Fig. 5) and the inline section is oriented nearly W-E (Sec3135; Fig. 6). Unless otherwise specified, all depths and elevations are given in meters below sea level ( $\mathrm{m}$ b.s.1.), in accordance with the figures. The surface at the COSC-1 drill site is located at $-522.8 \mathrm{~m}$ and the total depth of the 2495.8-m deep, nearly vertical borehole is at about $1973 \mathrm{~m}$. 
Table 1. Thomsen parameter models for the COSC-1 borehole location.

\begin{tabular}{lccccl}
\hline Model & $\varepsilon$ & $\gamma$ & $\delta$ & Model range (m b.s.l.) & Notes \\
\hline 1 & 0.03 & 0.02 & 0.3 & -500 to 2000 & Constant parameter model ${ }^{1}$ \\
1.1 & 0.03 & 0.02 & $0.03^{a}$ & -500 to 2000 & Same as model 1 with elliptical anisotropy \\
2 & 0.12 & 0.13 & $0.12^{a}$ & -500 to 2000 & Constant parameter model based on sample data ${ }^{2,3}$ \\
3 & 0.10 & 0.10 & $0.10^{a}$ & -500 to 2000 & Constant parameter model based on lithofacies \\
4 & 0.07 & 0.06 & $0.07^{a}$ & -500 to 1250 & Two-layer parameter model based on lithofacies ${ }^{4}$ \\
& 0.14 & 0.16 & $0.14^{a}$ & 1250 to 2000 & \\
ed & 0.089 & - & 0.023 & -500 to 1250 & Variable parameter model from velocity analysis of seismic field data. \\
& & & & & \\
& 0.133 & - & 0.044 & 1250 to 2000 & \\
\hline
\end{tabular}

${ }^{a}$ Models with elliptical anisotropy, i.e. where $\varepsilon=\delta$.

Notes: ${ }^{1}$ Simon et al. (2017); ${ }^{2}$ Wenning et al. (2016); ${ }^{3}$ Kästner et al. (2020a); ${ }^{4}$ Kästner et al. (2021).

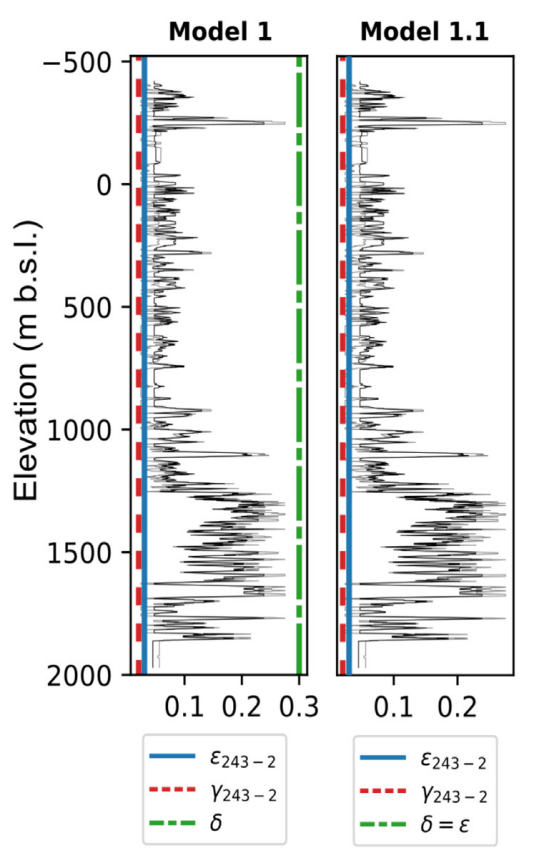

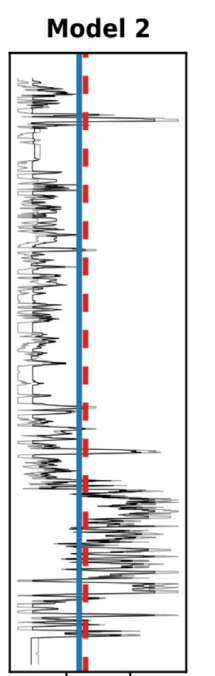
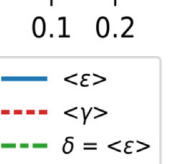

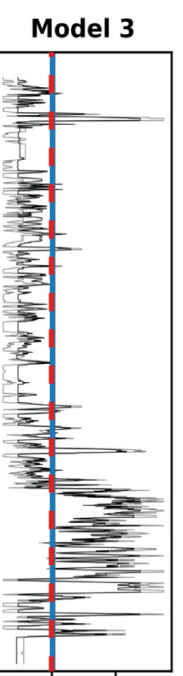

0.10 .2

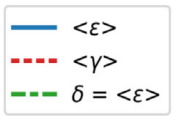

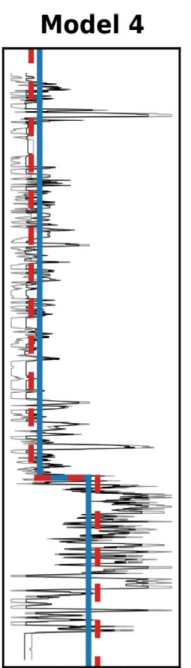

$0.1 \quad 0.2$

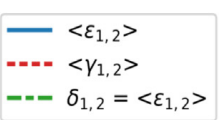

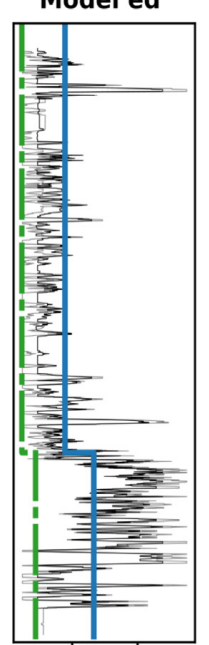

0.10 .2

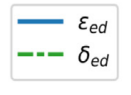

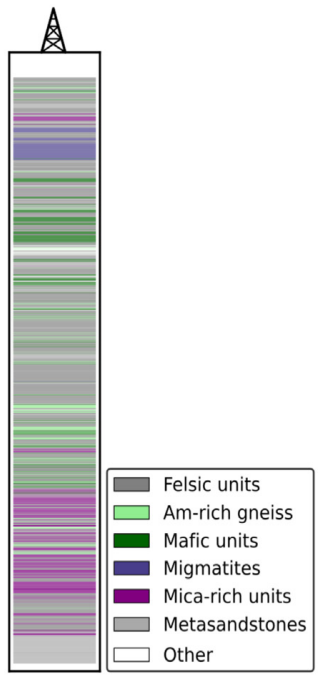

Simplified core lithology

Figure 3. Anisotropy models showing the Thomsen parameters used for the seismic imaging in this study. Model 1: based on Simon et al. (2017); model 1.1: like model 1 assuming elliptical anisotropy; model 2: constant parameter model based on the average anisotropy from 16 core samples (Wenning et al. 2016; Kästner et al. 2020a); model 3: constant parameter model averaged from 1-D anisotropy profiles for $P$ and $S$ waves indicated by black and grey curves (Kästner et al. 2021); model 4: two-layer parameter model averaged from 1-D anisotropy profile; model 'ed': variable anisotropy parameter model based on velocity analysis of seismic field data, here shown and averaged at the borehole location for comparison. The simplified core lithology is based on the COSC-1 core description (Lorenz et al. 2015a,b).

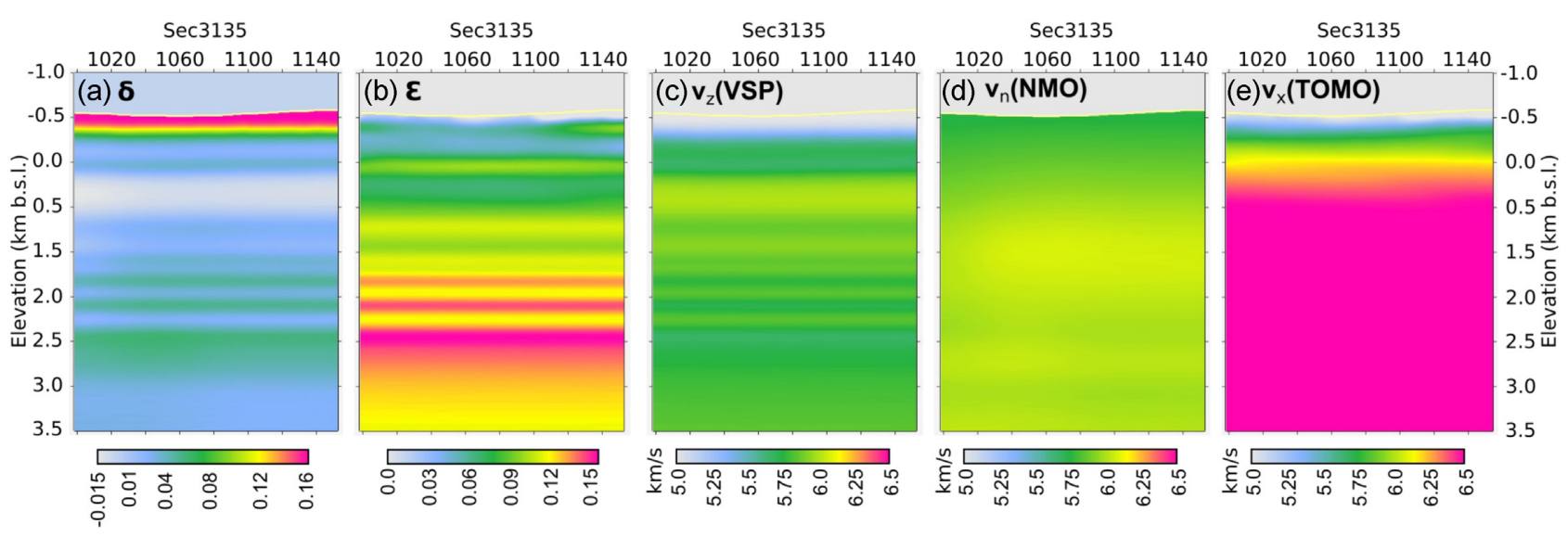

Figure 4. W-E section of the anisotropic velocity model used for seismic imaging at the COSC-1 borehole site. The Thomsen parameters $(\delta, \varepsilon)$ in (a) and (b) were derived from the smoothed zero-offset VSP (c), surface tomography (d) and short-spread NMO velocity data (e) from Hedin et al. (2016), Simon et al. (2017) and Krauß et al. (2020). 


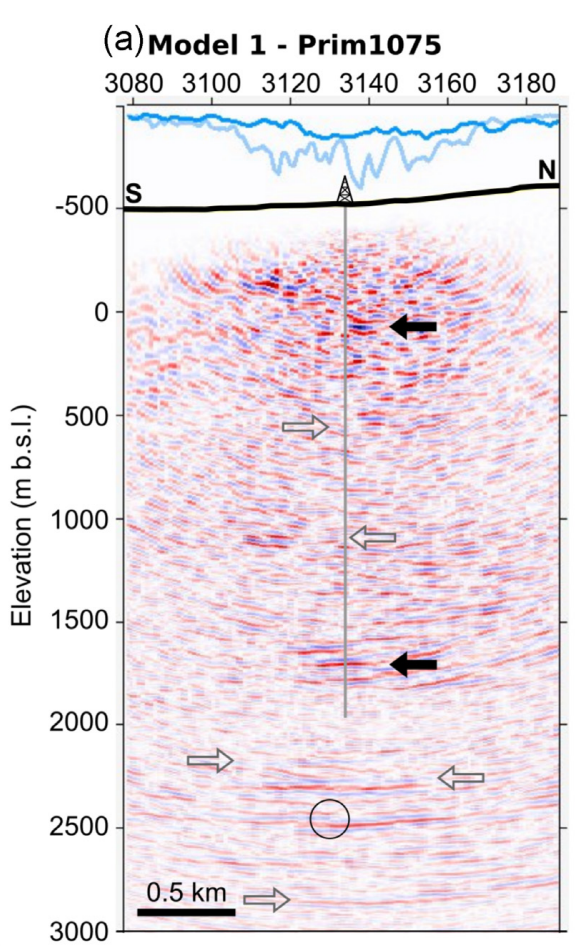

(b) Model 4 - Prim 1075

$\begin{array}{llllll}3080 & 3100 & 3120 & 3140 & 3160 & 3180\end{array}$
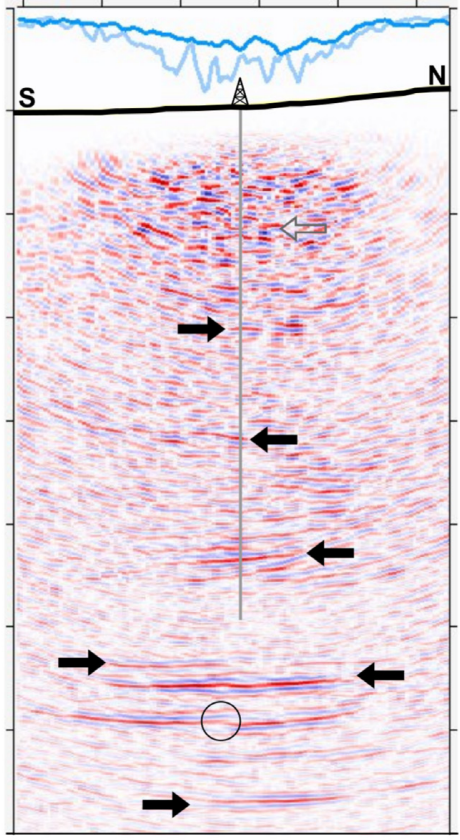

(c) Model ed - Prim 1075

$3080310031203140 \quad 31603180$
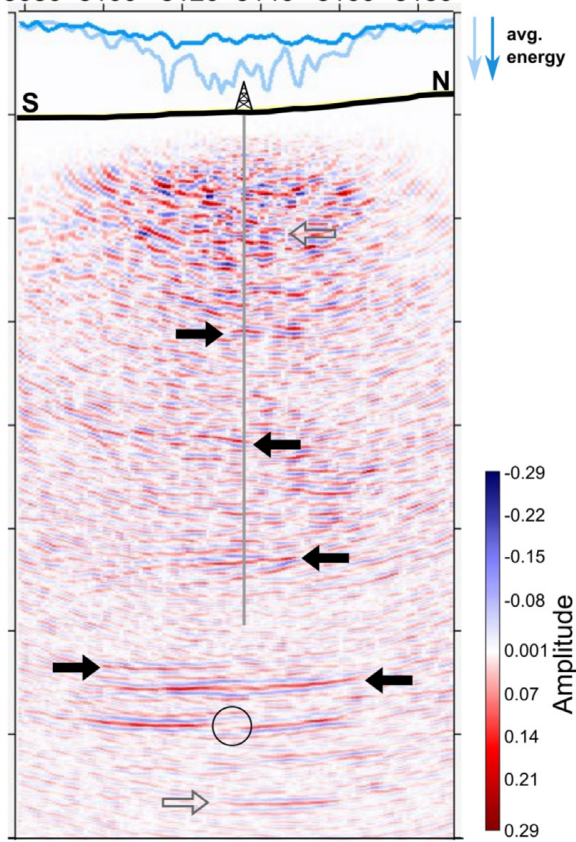

Figure 5. S-N seismic sections (Prim1075) after 3-D seismic reflection imaging at the COSC-1 borehole site using three different subsurface anisotropy parameter models and KPSDM. The two solid lines at the top show the average energy of each trace in the upper $1.7 \mathrm{~km}$ (light blue) and the depths below (dark blue). Arrows mark specific reflections on each section indicating where reflections are differently pronounced (filled: strong; transparent: weak or not visible). The circle highlights a change in the coherence of the reflections. The grey line marks the projected position of the COSC-1 borehole location. See Fig. 1 for the profile location.

(a) Model 1 - Sec3135

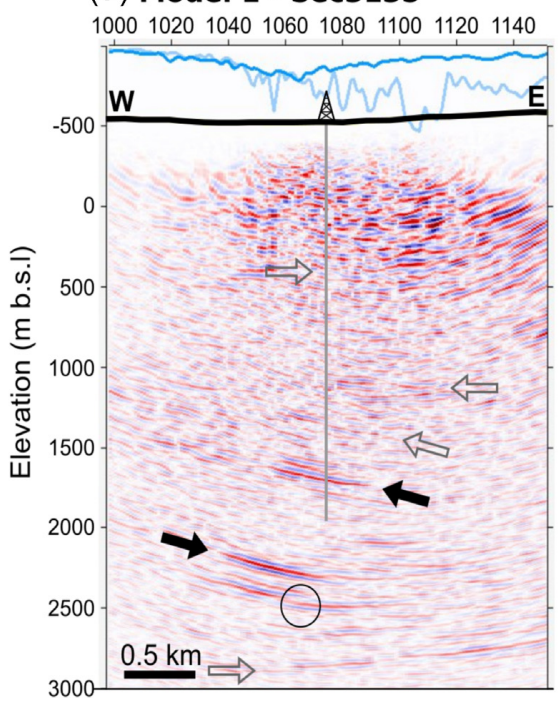

(b) Model 4 - Sec3135

10001020104010601080110011201140
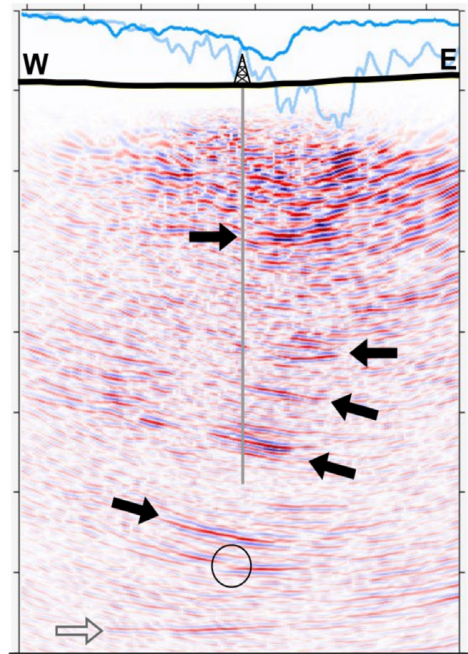

(c) Model ed - Sec3135

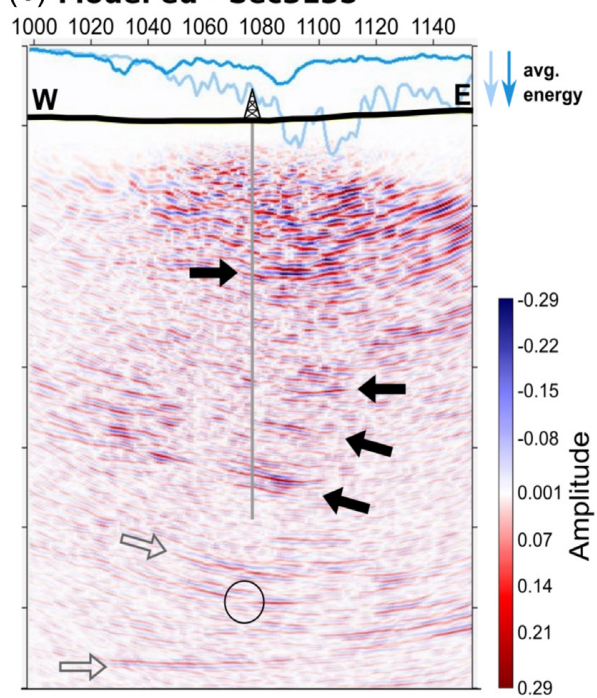

Figure 6. W-E seismic sections (Sec3135) after 3-D seismic reflection imaging at the COSC-1 borehole site using three different subsurface anisotropy parameter models and KPSDM. The two solid lines at the top show the average energy of each trace in the upper $1.7 \mathrm{~km}$ (light blue) and the depths below (dark blue). The grey line marks the projected position of the COSC-1 borehole location. Arrows mark specific reflections on each section indicating where reflections are differently pronounced (filled: strong; transparent: weak or not visible). The circle highlights a change in the coherence of the reflections. See Fig. 1 for the profile location.

The trace amplitudes of all shown sections were set to the same scale. As a quantitative measure, on top of each section two curves indicate the average energy of the upper and lower image area. The upper image area corresponds to layer 1 of the two-layer model (model 4), which extends from the surface to a depth of $1250 \mathrm{~m}$ (i.e. about $1.7 \mathrm{~km}$ below the surface). The image area below $1250 \mathrm{~m}$ corresponds to layer 2 in the two-layer model and extends to the bottom of the model.

We observe clear changes in the energy and continuity of reflections in the re-processed seismic images based on the different 
anisotropy models. Model 1, model 4, and model $e d$ reflect changes in the applied anisotropy parameters the most and therefore we focus on these results in the following (Figs 5 and 6). In addition and for reference, all sections including the other models are provided in the Supporting Information (Fig. S1).

The S-N 2-D seismic section (Prim1075) of the 3-D seismic image using model 1 (Fig. 5a) is characterized by an upper zone $(<500 \mathrm{~m})$ of high reflection amplitudes, with generally low continuity. Below this, reflectivity is less pronounced and reflection amplitudes are generally lower. While the average amplitude of the reflections generally decreases with depth, the lateral continuity of reflections increases indicating several reflections at about 1000 and $1750 \mathrm{~m}$ as well as two distinct reflections at 2250 and $2500 \mathrm{~m}$. The lateral reflection continuity (or coherence) is generally limited to about 0.5 to $1 \mathrm{~km}$. The inline section (Sec3135; Fig. 6a) shows similar characteristics, although the deeper reflections are dipping c. $20^{\circ}$ towards the east. The two deepest reflections (at c. 2250 and $2500 \mathrm{~m}$ ) show a pronounced reflection amplitude, which is highest at some distance away from the extrapolated borehole path.

Seismic imaging using the two-layer constant parameter model (model 4; Figs 5b and 6b) shows a clear separation of an uppermost highly reflective part characterized by a dense set of high-amplitude reflections with limited coherence; and a lower, less reflective part marked by more distinct reflections for both cross-line and inline sections. Especially, the cross-line section (Prim1075; Fig. 5b) indicates a more balanced amplitude distribution between the upper and lower part of the seismic section than in the previous described model. The lateral reflection continuity increases greatly below about $1000 \mathrm{~m}$ and allows delineation of reflections close to the edges of the section. Additional, pronounced reflections appear below c. $2200 \mathrm{~m}$ that are not previously seen with model 1 . In the inline section (Sec3135; Fig. 6b), some reflections between 500 and $1250 \mathrm{~m}$ appear more pronounced, especially east of the borehole location. A reflection not seen in model 1 , is now visible at about $800 \mathrm{~m}$, about $500 \mathrm{~m}$ east of the projected borehole. Even more pronounced is an almost continuous band of reflections between about 1250 and $1750 \mathrm{~m}$, which apparently dips at about $20^{\circ}$ to the east and terminates about $500 \mathrm{~m}$ east of the borehole location. The deepest reflections (below $2250 \mathrm{~m}$ ) show a strong coherence with a distinct lateral continuity of more than $1 \mathrm{~km}$. In contrast to the result using model 1, this double-reflection can be traced well below the borehole location. Amplitudes in the uppermost $1 \mathrm{~km}$ are clearly elevated at offsets east of the borehole. In the lower part, seismic amplitudes are much more balanced over all offsets showing a peak at the borehole location (see dark blue line in Fig. 6).

The reflection image based on the anisotropy model from velocity-analysis (model $e d$ ) is very similar to that of model 4 and is characterized by an even stronger reflective uppermost section and clear reflections in the lower section. Below $500 \mathrm{~m}$, the crossline section (Prim1075, Fig. 5c) indicates distinct reflections at for example about 500, 1000 and $1750 \mathrm{~m}$ as well as several coherent reflections below about $2200 \mathrm{~m}$. The reflection coherence is fairly similar to model 4, albeit showing some irregularities, for example, for the reflection at $2500 \mathrm{~m}$ depth. The inline section (Sec3135, Fig. 6c) indicates a series of reflections in the upper $1000 \mathrm{~m}(-500$ to $500 \mathrm{~m}$ ) with high-amplitude content and increased lateral continuity compared to model 1 . Within this uppermost zone, much of the amplitude content is concentrated east of the borehole location (also indicated by the light blue line in Fig. 6). At intermediate depths, between about 500 and $1250 \mathrm{~m}$, reflections are again only sparsely distributed and of little lateral extent. Only a few strong re- flections can be observed at about $1000 \mathrm{~m}$, extending at least $500 \mathrm{~m}$ away from the borehole. Similar to the reflection image of model 4, a pronounced band of reflections, which intersects the borehole at depths between 1250 and $1750 \mathrm{~m}$, enters at the western edge and spans more than half of the section with an eastward dip of about $20^{\circ}$. In contrast to models 1 and 4 , the eastward-dipping, double reflection that intersects the borehole at depths between 2250 and $2500 \mathrm{~m}$ appears less pronounced. The westward-dipping reflection near the base of the section is slightly less coherent than in the model 4 result, which for this reflection shows the highest coherence across the section.

\section{DISCUSSION}

The seismic sections can be divided into a series of major reflective units, at depths from -500 to $500 \mathrm{~m}, 500$ to $1000 \mathrm{~m}, 1000$ to $1250 \mathrm{~m}, 1750$ to $2250 \mathrm{~m}$ and below $2250 \mathrm{~m}$. The uppermost $1 \mathrm{~km}$ is largely characterized by incoherent, diffuse high-amplitude reflections in all models, while some more distinct and coherent reflections appear in models 4 and ed (Figs 5 and 6). Particularly interesting is the approximately $500-\mathrm{m}$ thick band of reflections below about $1250 \mathrm{~m}$ at the borehole location (predominantly seen in Sec3135, Fig. 6) that can be traced laterally for several kilometres westwards, at an angle of about 20 degrees. A number of highamplitude reflections around $1750 \mathrm{~m}$ indicate the lower boundary of this band of reflections. In the S-N direction (Prim1075), this band extends horizontally for at least several hundred meters away from the borehole. The limited extent in the $\mathrm{S}-\mathrm{N}$ direction is probably due to the lateral resolution and limited coverage of source locations, and possibly also the large variations in surface elevation in this direction. Moreover, among the constant parameter models (derived from core sample measurements) model 4 shows the best imaging results in terms of amplitude content and coherence of seismic reflections. While the results of models 2 and 3 are very similar, models 1 and 1.1 show some variations in the amplitude strength and lateral continuity of reflections as a result of different $\delta$ used in these two models. In direct comparison, these results emphasize that small changes in the input anisotropic parameters can have significant changes in the resulting amplitude content and coherency of reflections in metamorphic rocks with intermediate to high intrinsic anisotropy. Carefully chosen anisotropy parameters based on laboratory measurements of representative rock samples can thus improve the imaging and subsequent interpretation of the geometry of the tectonic structures or seismic stratigraphy.

The constant parameter models are based on the analysis of the seismic properties from laboratory core samples (Wenning et al. 2016; Kästner et al. 2020a). Consequently, these models represent only a 1-D approximation of the subsurface at the borehole location. Moreover, the sample-derived anisotropy values correspond to intrinsic anisotropy, which is caused by the mineral assemblage of the rocks excluding additional effects, such as oriented fractures or thin layering. Despite the limited lateral extent, these sample data provide a most robust way to estimate the in situ Thomsen parameters in the survey area, necessary for processing and calibration of the anisotropic imaging routines. In addition to the sample-based parameters, we determined a new anisotropy parameter model (model ed) based on the velocity analysis from surface seismic and borehole seismic data (Thomsen 1986; Alkhalifah \& Tsvankin 1995). This model is purely based on seismic field data. Thus, it provides a higher spatial sampling of the subsurface but also depends on seismic data quality, shot coverage, and NMO stability of the input 
seismic velocity fields. Nevertheless, using velocities from combined borehole and surface seismic data (model $e d$ ), even for this sparse 3-D seismic data set, provide reasonable results similar to those determined from laboratory sample analysis (model 4), giving confidence in both of the applied methods.

The applied anisotropy models are based on the assumption of a weak seismic anisotropy (Thomsen 1986). To test its effect on the reflection image, we therefore assumed a vertically transverse isotropic medium with values of $\varepsilon$ and $\delta$ much lower than 1 . According to Kästner et al. (2021), the latter is justified for most of the upper parts of the COSC-1 borehole, whereas the deeper borehole parts show considerably higher values of anisotropy (Fig. 3). However, Alkhalifah \& Larner (1994) indicated that the use of Thomsen's parameters is permissible even for media with higher anisotropy. While the transverse isotropic symmetry is a valid assumption for the mica-rich units, much of the upper units (amphibolite and felsic gneiss) at the borehole may also be described by a lower symmetry system, such as orthorhombic symmetry (Kästner et al. 2021). Despite these simplifications, we could observe a significant increase in the amplitudes and continuity of reflections.

Another simplification in our applied constant parameter models (models 1.1, 2, 3 and 4) is the use of elliptical anisotropy $(\varepsilon=$ $\delta$ ) assuming wave fronts to be elliptical (Fig. 2). Since $\delta$ was not determined by core sample analysis, we had to rely on $\delta$ derived from combined surface and borehole velocity fields. However, changes in the applied $\delta$ can have a noticeable impact on the reflection image as shown from the imaging results of models 1 and 1.1 (see Supporting Information Fig. S1). Here, model 1 used a comparably high $\delta$ of 0.3 (Simon et al. 2017), whereas model 1.1 used a $\delta$ of 0.03 . In addition, in model $e d, \delta$ was directly determined from the velocity fields of the surface and borehole seismic data. This model generally shows lower values of $\delta$ than $\varepsilon$, especially in the lower part of the borehole. The low $\delta$ values are caused by the low NMO velocities, $\mathrm{v}_{\mathrm{NMO}}$. They, even show a slight inversion below $2000 \mathrm{~m}$ (Fig. 4). As the NMO velocity is the least accurately determined velocity field, $\delta$ may also change significantly. That is, for example, by increasing the NMO velocities, $\delta$ will increase accordingly. However, in most parts of the borehole, $\delta$ agrees well with the elliptical models (Fig. 4). This is consistent with a very similar reflection image compared to that derived from the constant two-layer parameter model (model 4; Figs 5 and 6).

Results from migrating the seismic data using the individual isotropic velocities $\mathrm{v}_{\mathrm{VSP}}, \mathrm{v}_{\mathrm{NMO}}$ and $\mathrm{v}_{\mathrm{TOMO}}$ are shown in Fig. 7 (and Supporting Information Fig. S2). These images emphasize that at the borehole location, reflections are only imaged at the correct depths using the zero-offset velocities, vVSP. However, as seen in the $\mathrm{W}-\mathrm{E}$ profile (Sec3125; Fig. 7), the resulting migrated section has the weakest reflective energy. In contrast, most reflection energy is preserved using the isotropic velocity model $\mathrm{v}_{\text {Tомо }}$. Here, the reflections are too deep and do not coincide with the borehole data. The anisotropic model (e.g. model 4) fulfils both, maximum energy and correct depth position of the imaged reflections.

To further analyse the results of the migrated depth image in detail, we display in Fig. 8 a Common Image Gather (CIG) migrated with the anisotropic and isotropic models at a location close to the drill site. A correct velocity model must fulfil two requirements: (1) A target reflection migrates at the true depth (e.g. at $1250 \mathrm{~m}$ ) and (2) horizontal alignment of the reflection over the full offset range. The image using the VSP velocity VVSP (Fig. 8d) displays the target reflector at the correct depth but the velocity is too low as the reflection dips upward. By increasing the velocity by using the $\mathrm{v}_{\mathrm{NMO}}$ or $\mathrm{v}_{\mathrm{TOMO}}$ velocity field (Figs $8 \mathrm{e}$ and $\mathrm{f}$ ), the reflection gets more horizontally aligned but the reflection depth is imaged too deep. Both conditions are mostly fulfilled for the anisotropic models, where model 1 shows a slight downward dipping reflection and model $e d$ an upward dipping reflection. Model 4 shows the best result for both requirements, horizontal alignment and correct depth of the imaged reflection.

To summarize the previous discussion Fig. 9 highlights our approach for assess the effect of seismic anisotropy on the seismic reflection imaging at the COSC-1 borehole site by using different input data sets for the construction of a velocity model. This schematic outlines the effect on the migrated seismic reflection image (Fig. 7) and common image gather (Fig. 8) for both the isotropic velocity models and anisotropic velocity models derived from seismic field data and laboratory seismic measurements for comparison and verification of the imaging results.

Based on the regional COSC seismic profile, the Lower Seve Nappe was interpreted and characterized as a highly reflective syncline ( Figure 10a; Hedin et al. 2012; Juhlin et al. 2016), but due to the survey resolution, details of the internal nappe structure are barely visible. The more recent high-resolution 2-D and 3-D seismic surveys collected as part of the COSC-1 drilling project, revealed further details of the SNC and underlying structures resulting from Caledonian or pre-Caledonian deformations (Hedin et al. 2012; Simon et al. 2019). Our reprocessing of the 3-D seismic data using anisotropic velocity models revealed further internal features of the Lower Seve Nappe ( Figure 10b) suggesting a clear separation of major units in the seismic stratigraphy at the COSC-1 site. The highly reflective but still very diffuse uppermost section can be attributed to a distribution of mafic units (Elger et al. 2021), likely occurring in the form of boudins as observed in nearby outcrops (Hedin et al. 2016). These appear to be concentrated in irregularly elongated units or bands indicated by semi-continuous reflections, which can be traced up to the surface through combined 3-D and 2-D seismic data sets (Elger et al. 2021).

In addition to improving the resolution and imaging reflectors more accurately at their true subsurface location, our results show that differences within the upper $2.5 \mathrm{~km}$ of the reflection image are more clearly revealed when including anisotropic velocity models, especially at greater depths. In the upper parts of the borehole, these differences are less evident, but re-processing revealed changes in the dip and coherence of reflections further away from the borehole. The uppermost $800-1000 \mathrm{~m}$ of the borehole are likely less anisotropic, which is evident in the comparably low values of $\varepsilon$. With increasing depth, these reflections give way to a zone with little reflectivity characterized by low amplitudes and rather few reflections visible in the vicinity of the borehole location. At about $1250 \mathrm{~m}$, an about $500 \mathrm{~m}$-thick band of reflections cross-cuts the seismic section in W-E direction, dipping at $\sim 20$ degrees. At a similar depth of $1210 \mathrm{~m}$ (or $1710 \mathrm{~m}$ borehole depth), Hedin et al. (2016) proposed the onset of a 800 -m thick basal shear zone characterized by increasing mylonitization. The reflection seismic images of our study, however, suggest that the top of this band of reflections coincides with the onset of the unit predominantly comprising mica schist. The base of this mica-schist dominated unit coincides with a reflection at about $1750 \mathrm{~m}$ that marks the bottom of the band of reflections. The borehole shows that there is a metasedimentary unit underneath. Based on the core lithology (Lorenz et al. 2015a), we interpret the reflectivity in this band of reflections to be a result of the transition between mica schists and surrounding rock formations rather than the result of mylonitization. In agreement with the previous interpretations of the seismic 2-D survey (Hedin et al. 2012; Juhlin et al. 2016), we identify the transition from the Lower 


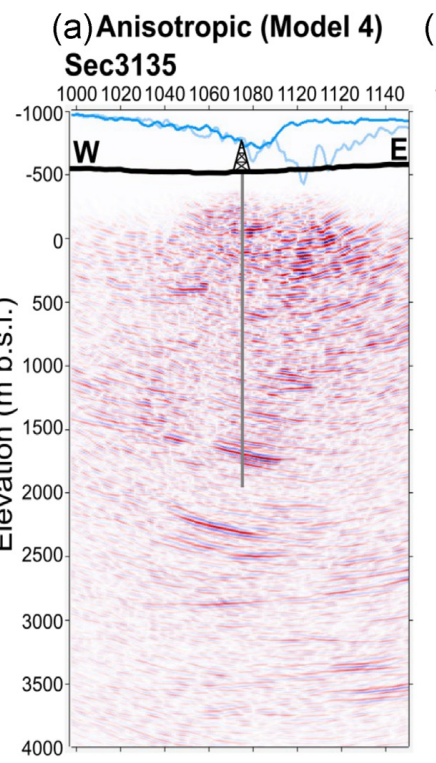

(b) Isotropic (VSP)

Sec3135

10001020104010601080112011201140

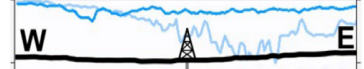

W

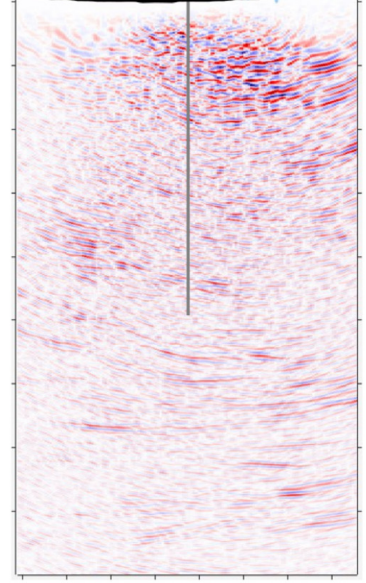

(c) Isotropic (NMO)

Sec3135

10001020104010601080112011201140

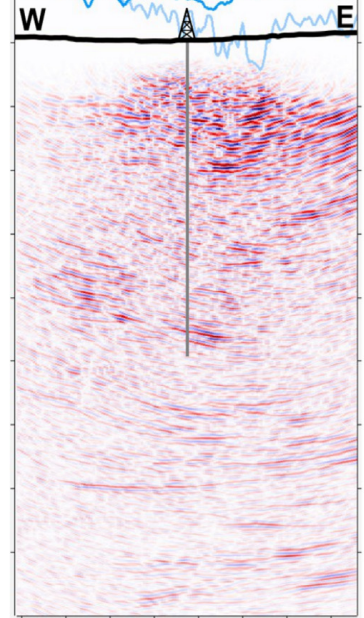

(d) Isotropic (TOMO)

Sec3135

10001020104010601080112011201140

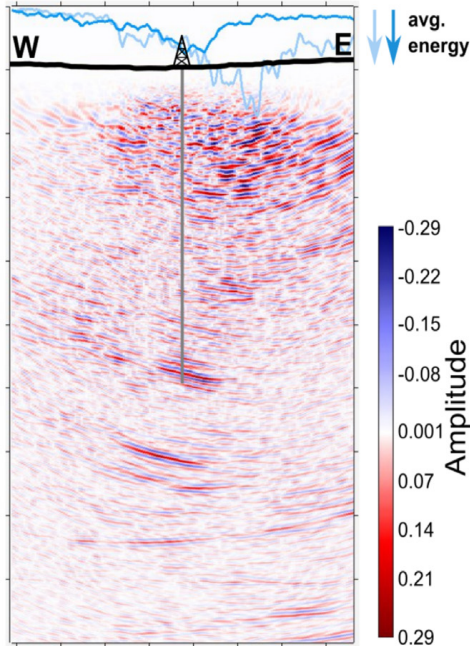

Figure 7. W-E seismic sections (Sec3135) after 3-D seismic reflection imaging at the COSC-1 drill site. Seismic migration was applied using an anisotropic velocity model (a) in comparison to isotropic velocity models (b-d) using zero-offset VSP velocities (b), 3-D normal moveout velocities (c; NMO) and 2-D tomography velocity data (d; TOMO). The two solid lines at the top show the average energy of each trace in the upper $1.7 \mathrm{~km}$ (light blue) and the depths below (dark blue). The grey line marks the projected position of the COSC-1 borehole location. See Fig. 1 for the location of the section.

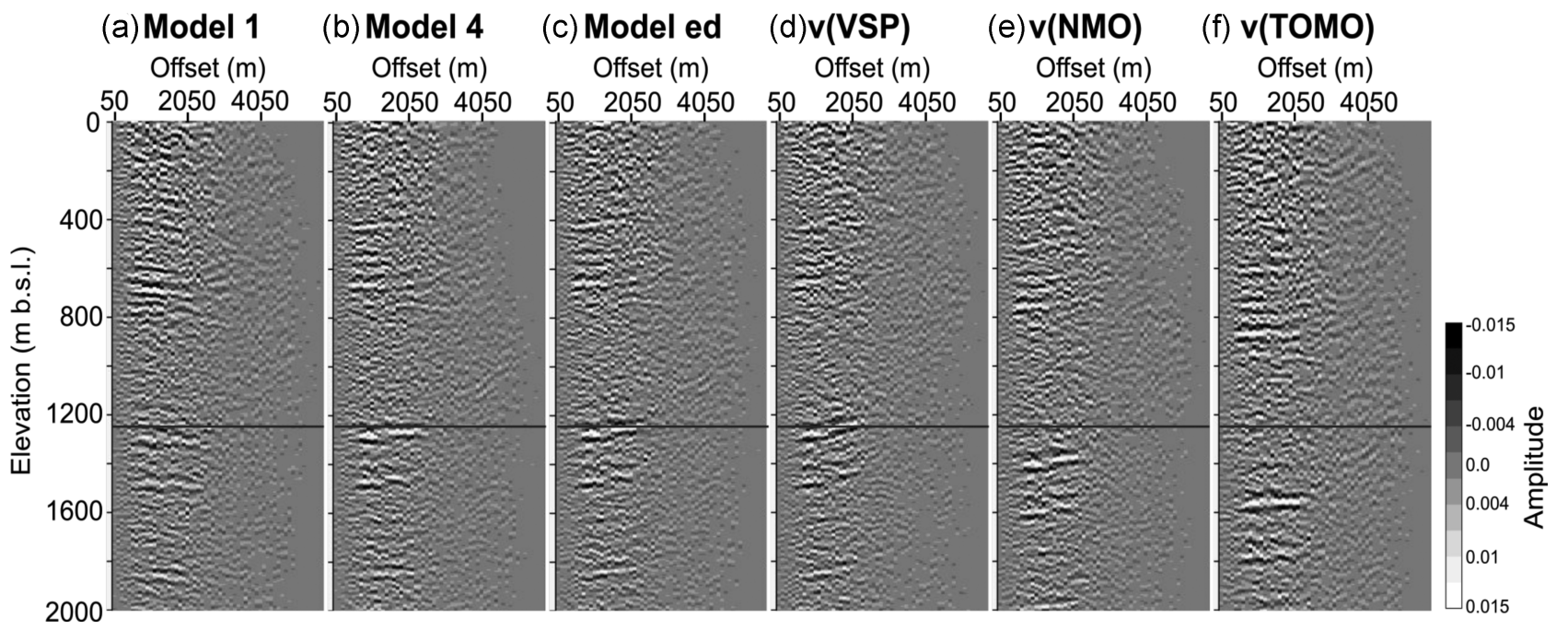

Figure 8. Common image gathers for different input velocity models (a-f) near the drill site at locations Prim1072 and Sec3135 (see Fig. 1) in the offset range from 0 to $6000 \mathrm{~m}$. The strongest horizontal alignment of a reflector at $1250 \mathrm{~m}$ target depth (horizontal line) is achieved for model 4 .

Seve Nappe into the underlying Särv/Offerdal Nappes at depths of about $1750 \mathrm{~m}$ (directly below the reflective mica schist unit) and the transition into the Ordovician turbidities of the Lower Allochthon about $250 \mathrm{~m}$ below the borehole. These reflections at depths below the borehole are generally well-pronounced showing a pervasive lateral continuity.

Based on our results we conclude that the seismic stratigraphy is strongly influenced by anisotropic velocity effects, which must be considered for reflection processing and imaging to be successful. The presented reflection images indicate that incoherent, high-amplitude reflections are limited to the uppermost $800 \mathrm{~m}$, associated with mafic boudinage structures. These mafic boudins can occur at different dips and various shapes and sizes, and at scales that are relatively small compared to the seismic resolution (Lorenz et al. 2015b; Hedin et al. 2016). In combination with a strong impedance contrast between these mafic rocks and the surrounding felsic gneiss, they can cause considerable seismic scattering also including out-of-plane reflections, thus, hampering a more detailed seismic imaging of this uppermost unit. Further below, reflection coherence increases significantly. This suggests an internal stratigraphy of the Lower Seve Nappe at the COSC-1 borehole site caused by lithological changes in the subsurface.

\section{CONCLUSIONS}

We have determined seismic anisotropy parameters from sparse 3$\mathrm{D}$ reflection seismic data in combination with velocity data from borehole seismic experiments and surface tomography data at the COSC-1 borehole site. Despite the 3-D seismic data set's limitations 
Input data

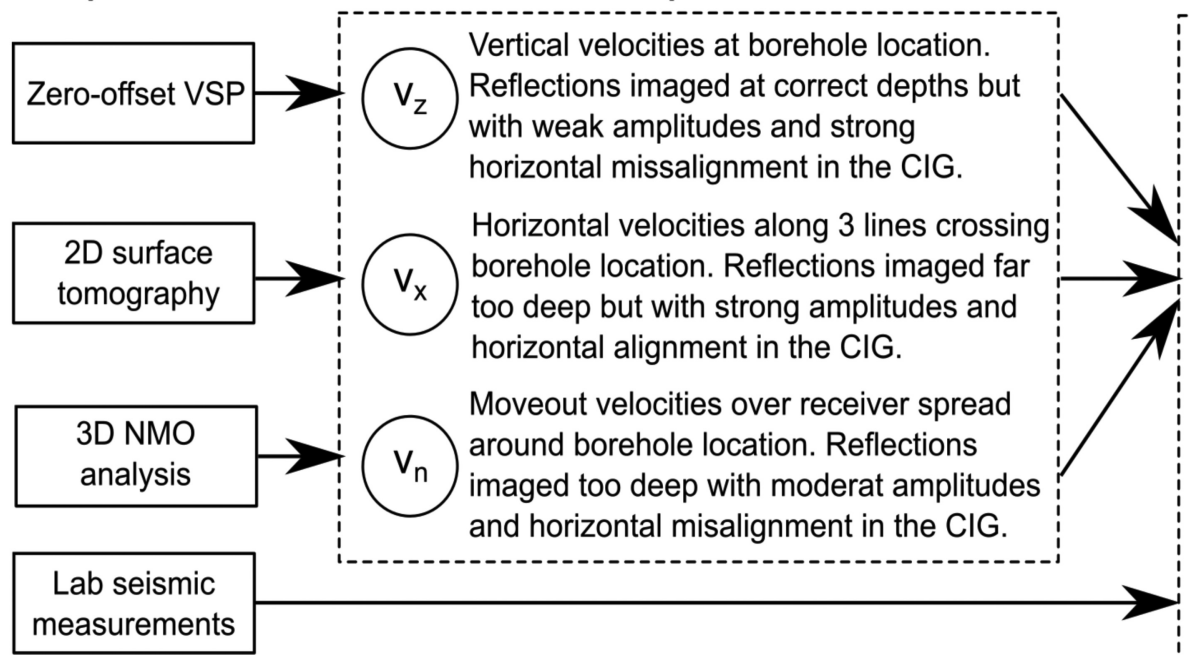

Anisotropic v-models

Anisotropic velocity models based on field and laboratory data. Reflections are imaged at correct depths with strong amplitudes and horizontal alignemnt in the CIG.

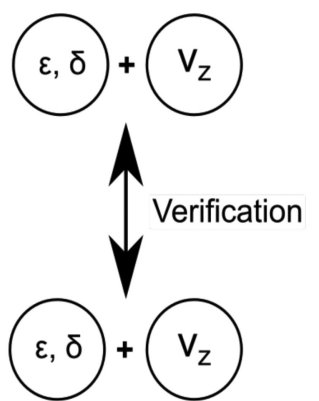

Figure 9. Schematic summarizing the used velocity input data and its effects on the seismic imaging from migrated depth imaging and common image gather at the COSC-1 borehole site.

(a)

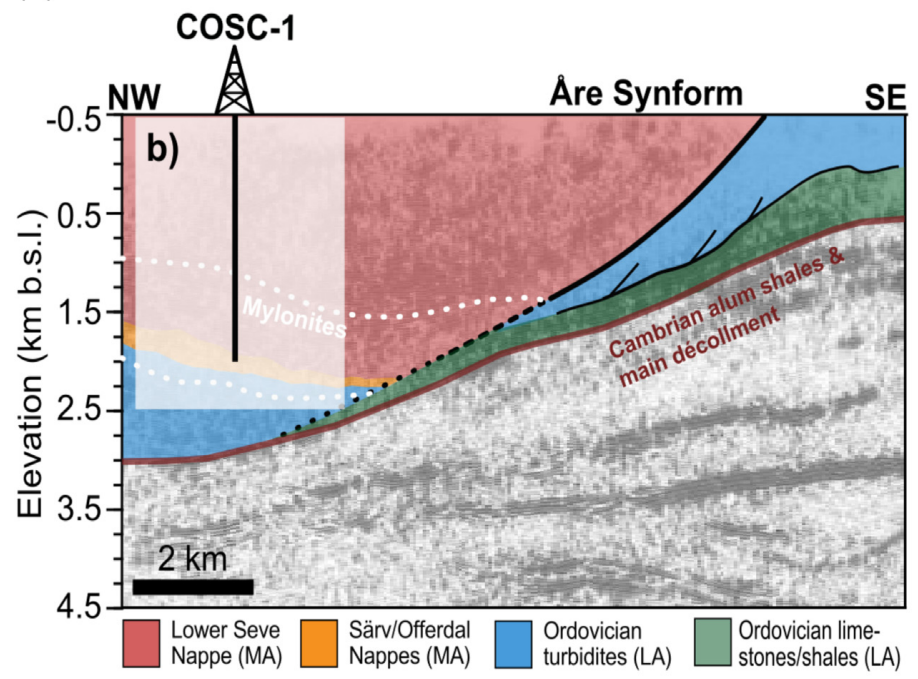

(b)

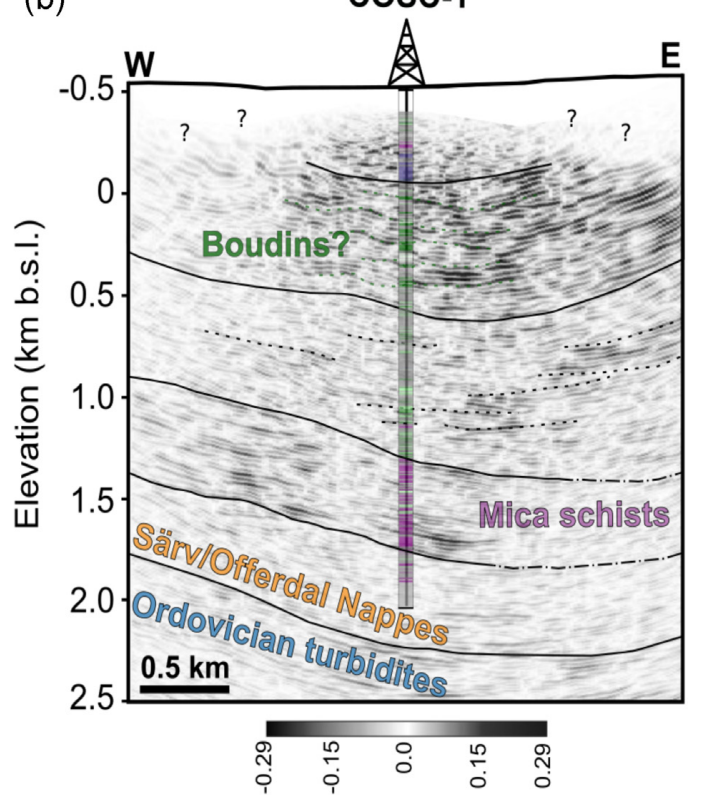

Figure 10. Interpretation of the seismic stratigraphy of the Lower Seve Nappe and underlying tectonic units. (a) Section of the 2-D COSC seismic profile interpreted in relation to the tectonostratigraphy of the central Scandinavian Caledonides in western Jämtland, Sweden (Hedin et al. 2012; Juhlin et al. 2016). (b) Re-processed and interpreted 2-D seismic section at the COSC-1 borehole site based on limited 3-D seismic data (Hedin et al. 2016), here processed and imaged using an anisotropic velocity model from VSP and seismic field data (model $e d$ ). At the borehole location, the lithofacies profile is shown based on the COSC-1 core lithology (modified from Lorenz et al. 2015a).

in offset and fold, the derived anisotropy parameters are comparable to the results from laboratory measurements on core samples. Both laboratory and field data indicate a similar, major two-layer anisotropy model at the COSC-1 site. This shows that within intrinsically anisotropic metamorphic rocks, a combined analysis of borehole seismic and sparse surface seismic data can give satisfactory results.

Using varying anisotropic parameters, imaging of the 3-D seismic using anisotropic Kirchhoff pre-stack depth migration reveals significant changes in the resulting reflection images. Our results suggest that the sample-derived two-layer model and combined borehole-surface model provide the best imaging results in terms of amplitude content and reflection coherence, and are in good agreement with the depths of major lithological units at the borehole location. Especially, in the deeper parts of the borehole, below $1.2 \mathrm{~km}$, high-amplitude reflections appear more continuous, providing a higher confidence in the lateral extent of reflections. Moreover, the resulting reflection image enables a better separation of stratigraphic units within the Lower Seve Nappe that are in good agreement with the core lithology of the COSC-1 borehole. Limitations in the acquisition geometry, however, prevent a more detailed resolution of small-scale subsurface features, which would require more extensive 3-D seismic field campaigns. Our results will aid the interpretation of the high-amplitude reflectivity of the 
Lower Seve Nappe in Jämtland and potentially also other parts of the Caledonides.

\section{ACKNOWLEDGEMENTS}

This research was funded by the German Research Foundation (DFG, Project no. 339380967, SPP-1006). The COSC-1 drilling project was supported by the International Continental Scientific Drilling Program (ICDP) and the Swedish Research Council (VR - Grant 2013-94) using the national research infrastructure for scientific drilling Riksriggen. The acquisition of the 3-D seismic reflection data was partly funded by Swedish Research Council (VR - Grant 2013-5780). We thank Helge Simon for providing the surface tomography data and for his helpful remarks during data preparation. We also thank the two anonymous reviewers for their important remarks helping to improve our manuscript.

\section{DATA AVAILABILITY}

Seismic laboratory measurements of the COSC-1 core samples are available from the GFZ Data Services online repository (see Kästner et al. 2020b). We thank Uppsala University for providing the 3-D seismic data originally published by Hedin et al. (2016). We thank TU Bergakademie Freiberg for providing the 2-D tomography data that were first published by Simon et al. (2017).

\section{REFER EN CES}

Alkhalifah, T. \& Larner, K., 1994. Migration error in transversely isotropic media, Geophysics, 59, 1405-1418.

Alkhalifah, T. \& Tsvankin, I., 1995. Velocity analysis for transversely isotropic media, Geophysics, 60, 1550-1566.

Almqvist, B.S.G., Hirt, A.M., Herwegh, M., Ebert, A., Walter, J.M., Leiss, B. \& Burlini, L., 2013. Seismic anisotropy in the Morcles nappe shear zone: implications for seismic imaging of crustal scale shear zones, Tectonophysics, 603, 162-178.

Bleistein, N., Stockwell, J.W. \& Cohen, J.K., 2001. Mathematics of Multidimensional Seismic Imaging, Migration, and Inversion. Appl. Mech. Rev., Vol. 13, Springer Science and Business Media.

Elapavuluri, P. \& Bancroft, J.C., 2002. Estimation of Thomsen's anisotropy parameter $\delta$ and $\varepsilon$ using EO gathers, CREWES Res. Rep., 14, $1-18$.

Elger, J., Berndt, C., Kästner, F., Pierdominici, S., Kück, J., Almqvist, B.S.G., Juhlin, C. \& Henning, L., 2021. Core-log-seismic integration in metamorphic rocks and its implication for the regional geology: a case study for the ICDP drilling project COSC-1, Sweden, Geochem. Geophys. Geosyst., 22, e2020GC009376, doi:10.1029/2020GC009376

Gaiser, J.E., 1990. Transversely isotropic phase velocity analysis from slowness estimates, J. geophys. Res., 95, 11241.

Gee, D.G., Fossen, H., Henriksen, N. \& Higgins, A.K., 2008. From the early Paleozoic platforms of Baltica and Laurentia to the Caledonide Orogen of Scandinavia and Greenland, Episodes, 31, 44-51.

Gee, D.G., Juhlin, C., Pascal, C. \& Robinson, P., 2010. Collisional Orogeny in the Scandinavian Caledonides (COSC), GFF, 132, 29-44.

Gee, D.G., Janák, M., Majka, J., Robinson, P. \& van Roermund, H., 2013. Subduction along and within the Baltoscandian margin during closing of the Iapetus Ocean and Baltica-Laurentia collision, Lithosphere, 5, 169178.

Gray, S.H., 2013. Spatial sampling, migration aliasing, and migrated amplitudes, Geophysics, 78, S157-S164.

Grechka, V., Mateeva, A., Gentry, C., Jorgensen, P., Lopez, J. \& Franco, G., 2007. Estimation of seismic anisotropy from P-wave VSP data, Leading Edge, 26, 756-759.
Hedin, P., Juhlin, C. \& Gee, D.G., 2012. Seismic imaging of the Scandinavian Caledonides to define ICDP drilling sites, Tectonophysics, 554-557, 3041.

Hedin, P. et al., 2016. 3D reflection seismic imaging at the $2.5 \mathrm{~km}$ deep COSC-1 scientific borehole, central Scandinavian Caledonides, Tectonophysics, 689, 40-55.

Isaac, J.H. \& Lawton, D.C., 2004. A practical method for estimating effective parameters of anisotropy from reflection seismic data, Geophysics, 69, 681-689.

Juhlin, C., Hedin, P., Gee, D.G., Lorenz, H., Kalscheuer, T. \& Yan, P., 2016. Seismic imaging in the eastern Scandinavian Caledonides: siting the 2.5 km deep COSC-2 borehole, central Sweden, Solid Earth, 7, 769-787.

Juhojuntti, N., Juhlin, C. \& Dyrelius, D., 2001. Crustal reflectivity underneath the Central Scandinavian Caledonides, Tectonophysics, 334, 191210.

Kästner, F., Pierdominici, S., Elger, J., Zappone, A., Kück, J. \& Berndt, C., 2020a. Correlation of core and downhole seismic velocities in highpressure metamorphic rocks: a case study for the COSC-1 borehole, Sweden, Solid Earth, 11, 607-626.

Kästner, F. et al., 2020b. Seismic properties and mineralogy of core samples from the COSC-1 borehole, Sweden, GFZ Data Services, doi:10.5880/GFZ.4.2.2020.009.

Kästner, F., Pierdominici, S., Zappone, A., Morales, L.F.G., Schleicher, A.M., Wilke, F.D.H. \& Berndt, C., 2021. Cross-scale seismic anisotropy analysis in metamorphic rocks from the COSC-1 borehole in the Scandinavian Caledonides, J. geophys. Res., 126, doi:10.1029/2020JB021154.

Krauß, F., 2018. Combination of Borehole Seismic and Downhole Logging to Investigate the Vicinity of the COSC-1 Borehole in Western Scandinavia, TU Bergakademie Freiberg.

Krauß, F., Giese, R., Simon, H. \& Buske, S., 2020. Zero-offset vertical seismic profiling (VSP) data from the COSC-1 borehole, Sweden, GFZ Data Services, doi:10.5880/GFZ.4.2.2020.010.

Ladenberger, A., Be'eri-Shlevin, Y., Claesson, S., Gee, D.G., Majka, J. \& Romanova, I. V., 2014. Tectonometamorphic evolution of the Åreskutan Nappe - Caledonian history revealed by SIMS U-Pb zircon geochronology, Geol. Soc. London, Spec. Publ., 390, 337-368.

Liu, J., Xia, J., Chen, C. \& Zhang, G., 2005. Accurate elevation and normal moveout corrections of seismic reflection data on rugged topography, N.Z. J. Geol. Geophys., 48, 707-716.

Lorenz, H. et al., 2015a. COSC-1 operational report—operational data sets, GFZ Data Services, doi:10.1594/GFZ.SDDB.ICDP.5054.2015.

Lorenz, H. et al. 2015b. COSC-1 - drilling of a subduction-related allochthon in the Palaeozoic Caledonide orogen of Scandinavia, Sci. Drill., $19,1-11$.

Schneider, W.A., 1978. Integral formulation for migration in two and three dimensions, Geophysics, 43, 49-76.

Simon, H., Buske, S., Krauß, F., Giese, R., Hedin, P. \& Juhlin, C., 2017. The derivation of an anisotropic velocity model from a combined surface and borehole seismic survey in crystalline environment at the COSC-1 borehole, central Sweden, Geophys. J. Int., 210, 1332-1346.

Simon, H., Buske, S., Hedin, P., Juhlin, C., Krauß, F. \& Giese, R., 2019. Anisotropic Kirchhoff pre-stack depth migration at the COSC-1 borehole, central Sweden, Geophys. J. Int., 219, 66-79.

Thomsen, L., 1986. Weak elastic anisotropy, Geophysics, 51, 1954-1966.

Tsvankin, I., Gaiser, J., Grechka, V., Van der Baan, M. \& Thomsen, L., 2010. Seismic anisotropy in exploration and reservoir characterization: an overview, Geophysics, 75, 75A15-75A29.

Wenning, Q.C., Almqvist, B., Hedin, P. \& Zappone, A., 2016. Seismic anisotropy in mid to lower orogenic crust: insights from laboratory measurements of Vp and Vs in drill core from central Scandinavian Caledonides, Tectonophysics, 692, 14-28.

White, J.E., Martineau-Nicoletis, L. \& Monash, C., 1983. Measured anisotropy in Pierre Shale, Geophys. Prospect., 31, 709-725.

Xiao, C.M., Bancroft, J.C. \& Brown, R.J., 2005. Estimation of Thomsen's anisotropy parameters by moveout velocity analysis, in SEG Technical Program Expanded Abstracts 2005, pp. 194-197, Society of Exploration Geophysicists, doi:10.1190/1.2142223. 
Yilmaz, Ö., 2001. Seismic Data Analysis, Vol. 1, Society of Exploration Geophysicists.

Zhang, Y., Gray, S. \& Young, J., 2000. Exact and approximate weights for Kirchhoff migration, in 2000 SEG Annual Meeting, Society of Exploration Geophysicists, doi:10.1190/1.1815561

\section{SUPPORTING INFORMATION}

Supplementary data are available at GJI online.

Figure S1. S-N (Prim1075) and W-E (Sec3135) seismic sections after 3-D seismic reflection imaging at the COSC-1 borehole site using six different subsurface anisotropy parameter models and KPSDM. The two solid lines at the top show the average energy of each trace in the upper $1.7 \mathrm{~km}$ (light blue) and below (dark blue). See Fig. 1 for the location of the profile.
Figure S2. S-N seismic section (Prim1075) after 3-D seismic reflection imaging at the COSC-1 borehole site. Seismic migration was applied using an anisotropic velocity model (a) in comparison to isotropic velocity models (b-d) using zero-offset VSP velocities (b), 3-D normal moveout velocities (c; NMO) and 2-D tomography velocity data (d; TOMO). The two solid lines at the top show the average energy of each trace in the upper $1.7 \mathrm{~km}$ (light blue) and the depths below (dark blue). The grey line marks the projected position of the COSC-1 borehole location. See Fig. 1 for the location of the section.

Please note: Oxford University Press is not responsible for the content or functionality of any supporting materials supplied by the authors. Any queries (other than missing material) should be directed to the corresponding author for the paper. 